\section{AB0454 CHARACTERISTIC ULTRASOUND FEATURES OF SALIVARY GLAND LYMPHOMA IN PATIENTS WITH PRIMARY SJÖGREN'S SYNDROME}

S. Zhang ${ }^{1}$, Y. Liu ${ }^{1}$, D. Lii ${ }^{1}$, W. Li ${ }^{1}$, J. Zhu ${ }^{1} .{ }^{1}$ Peking University People's Hospital, Department of Ultrasound, Beijing, China

Background: Lymphoma was one of the most severe complications of primary Sjögren's syndrome (pSS). Lymphomas often developed in organs where pSS is active, such as salivary glands. The enlargement of salivary glands is considered a predictive factor in previous studies. It is clarified that salivary gland ultrasound can visually and clearly demonstrate the parenchyma structure, which is a feasible method for SS diagnosis. However, there are no specific ultrasound features of salivary gland lymphoma and no early ultrasonic alarming system have been reported.

Objectives: To descript the characteristic ultrasound features and assess ultrasonic alarming value of salivary gland lymphoma in patients with pSS.

Methods: We followed a cohort of 63 patients with pSS from March 2017 to September 2019 and salivary gland ultrasound was performed every three months. All patients were examined by grey-scale and color Doppler ultrasound (US). The size, echostructure and vascularity of salivary glands were analyzed. US-guided core-needle biopsy (US-CNB) was used for the diagnosis of salivary gland lymphoma.

Results: In 63 patients with pSS, parotid enlargement occurred in 11 patients and none of them had submandibular gland enlargement. During the follow-up, 2 patients with parotid enlargement demonstrated recovery of size and echostructure improved. The remaining 9 patients had permanent parotid swelling and echostructure unchanged. US-CNB was performed in these 9 patients and histological and immunohistochemical findings of the cores suggested parotid lymphoma. Compared with other patients, these 9 patients revealed marked, permanent parotid enlargement of the unilateral or bilateral or asymmetric parotid. The parotid lymphoma ultrasonography was characterized by multiple, relatively large, well-demarcated hypoechoic $(>6 \mathrm{~mm})$ with increased vascularity. Conclusion: Ultrasonographic assessment of salivary gland helped to alarm the occurrence of lymphoma in pSS patients. Marked, permanent and asymmetric parotid enlargement with multiple, relatively large, well-demarcated hypoechoic in echostructure seemed to be characteristic for parotid lymphoma in pSS patients.

References:

[1] Theander E, Henriksson G, Ljungberg O, Mandl T, Manthorpe R, Jacobsson LT. Lymphoma and other malignancies in primary Sjögren's syndrome: a cohort study on cancer incidence and lymphoma predictors. Ann Rheum Dis. 2006;65(6):796-803.

[2] Nocturne G, Mariette X. Sjögren's Syndrome-associated lymphomas: an update on pathogenesis and management. $\mathrm{Br} \mathrm{J}$ Haematol. 2015; 168(3):317-27.

[3] Alunno A, Leone MC, Giacomelli R, Gerli R, Carubbi F. Lymphoma and lymphomagenesis in primary Sjögren's syndrome. Front Med (Lausanne). 2018;5:102.

[4] Orita Y, Sato Y, Kimura N, Marunaka H, Tachibana T, Yamashita Y, et al. Characteristic ultrasound features of mucosa-associated lymphoid tissue lymphoma of the salivary and thyroid gland. Acta Otolaryngol. 2014;134(1):93-9.

Disclosure of Interests: None declared

DOI: 10.1136/annrheumdis-2020-eular.5193

\section{AB0455 HEMATOLOGICAL PARAMETERS AS THE MARKERS OF DISEASE ACTIVITY IN PATIENTS WITH SYSTEMIC LUPUS ERYTHEMATOSUS}

V. Živković ${ }^{1,2}$, B. Stamenković ${ }^{1,2}$, S. Stojanović ${ }^{1,2}{ }^{1}{ }^{1}$ University of Niš, Faculty of Medicine, Niš, Serbia; 'Institute for Treatment and Rehabilitation "Niška Banja", Niš, Serbia

Background: As the standard markers of systemic inflammation in autoimmune diseases erythrocyte sedimentation rate (ESR) and C-reactive protein (CRP) are usually used, but in recent years there have been conflicting results about the potential significance of neutrophil to lymphocyte ratio (NLR) and platelet to lymphocyte ratio (PLR).

Objectives: Our aim was to investigate the correlation of NLR and PLR with disease activity in patients with systemic lupus erythematosus (SLE).

Methods: The study involved 160 patients with SLE (145 women and 15 men), hospitalized in the Clinic of Rheumatology, Institute "Niška Banja“, aged on the average $46.34 \pm 10.82$ years and with average disease duration of $9.76 \pm 8.27$ years, in whom the diagnosis was established based on the revised ACR criteria from 1997. In addition to clinical examination and supplementary tests, their disease activity was assessed using the Systemic Lupus Erythematosus Disease Activity Index (SLEDAI), together with determination of NLR and PLR.
Results: In SLE patients, there was a positive correlation of NLR with ESR $(r=0.212 ; p=0.010)$, anti-dsDNA antibodies $(r=0.185 ; p=0.025)$, and PLR $(r=0.601$ $\mathrm{p}<0.001$ ), as well as a negative correlation with complement component 3 (C3) $(r=-0.264 ; p=0.003)$. Further, there was a positive correlation of PLR with ESR $(r=0.329 ; p<0.001)$, CRP $(r=0.249 ; p=0.003)$, anti-dsDNA antibodies $(r=0.280$ $\mathrm{p}=0.001$ ), anti-nucleosome antibodies $(\mathrm{r}=0.263 ; \mathrm{p}=0.026)$, and values of urinary chemoattractant protein-1 (MCP1) $(r=0.263 ; p=0.043)$, as well as a negative correlation with $\mathrm{C} 3(\mathrm{r}=-0.276 ; \mathrm{p}=0.002)$. Our univariate analysis demonstrated that not only the values of ESR, CRP, C3, anti-dsDNA, anti-nucleosome, anti-C1a antibodies, serum and urinary MCP1 $(p<0.001)$ were statistically significantly associated with SLEDAl, but also the NLR $(p<0.001)$ and PLR $(p<0.001)$. Using the method of standard multiple regression analysis, we examined the impact of the above parameters on SLEDAI. The examined model accounted for $21.7 \%$ of variance in activity index (corrected $r^{2}=0.217, F=2.525, p=0.017$ ). As the statistically significant risk factors, ESR (Beta $=0.394, p=0.020)$ and serum MCP1 (Beta $=0.325, p=0.043$ ) stood out.

Conclusion: NLR and PLR, as hematological parameters available in everyday clinical work, can be significant for disease activity assessment in SLE patients. References:

[1] Gasparyan AY, Ayvazyan L, Mukanova U, Yessirkepov M, Kitas GD. The Platelet-to-Lymphocyte Ratio as an Inflammatory Marker in Rheumatic Diseases. Ann Lab Med. 2019;39(4):345-57.

[2] Yu H, Jiang L, Yao L, Gan C, Han X, Liu R, Su N. Predictive value of the neutrophil-to-lymphocyte ratio and hemoglobin in systemic lupus erythematosus. Exp Ther Med. 2018;16(2):1547-53.

[3] Wu Y, Chen Y, Yang X, Chen L, Yang Y. Neutrophil-to-lymphocyte ratio (NLR) and platelet-to-lymphocyte ratio (PLR) were associated with disease activity in patients with systemic lupus erythematosus. Int Immunopharmacol. 2016;36:94-9

[4] Yolbas S, Yildirim A, Gozel N, Uz B, Koca SS. Hematological Indices May Be Useful in the Diagnosis of Systemic Lupus Erythematosus and in Determining Disease Activity in Behcet's Disease. Med Princ Pract. 2016;25(6):510-6.

[5] Qin B, Ma N, Tang Q, Wei T, Yang M, Fu H, Hu Z, Liang Y, Yang Z, Zhong R Neutrophil to lymphocyte ratio (NLR) and platelet to lymphocyte ratio (PLR) were useful markers in assessment of inflammatory response and disease activity in SLE patients. Mod Rheumatol. 2016;26(3):372-6.

Disclosure of Interests: None declared

DOI: 10.1136/annrheumdis-2020-eular.2501

\section{Vasculitis}

\section{AB0456 \\ ROLE OF CYTOKINES (INTERLEUKIN 17 AND 23) IN PSYCHIATRIC COMORBIDITIES ASSOCIATED WITH BECHET'S DISEASE}

E. Abdelmoty ${ }^{1}$, M. Gaber ${ }^{2}$, R. Gabra ${ }^{3}$, E. Abda ${ }^{4}$, S. Rashad ${ }^{5} .{ }^{1}$ Assiut University Hospitals, Rheumatology, Rehabilitation and Physical medicine, Asyut, Egypt;

${ }^{2}$ Medical Faculty, Asyut University, Biochemistry, Asyut, Egypt; ${ }^{3}$ Assiut University Hospitals, Psychiatry, Asyut, Egypt: ${ }^{4}$ Assiut University Hospitals, Physical Medicine, Rheumatology \& Rehabilitation, Asyut, Egypt; ${ }^{5}$ Suiz University, Rheumatology and Rehabilitation, Suiz, Egypt

Background: Behcet's disease (BD) is a chronic multi-systemic autoinflammatory disease associated with increase prevalence of psychiatric comorbidity (Ilhan et al. 2016). Pro-inflammatory cytokines have been reported to be elevated in patients with depression and anxiety. IL-23/IL-17 axis has been shown to play a remarkable role in pathogenesis of $\mathrm{BD}$, depression and anxiety (Sugita et al. 2012, Gheita et al. 2015). However, the relation between the serum level of interleukin (IL)-17 and IL-23 and incidence of cognitive impairment, depression and anxiety in Behcet patients are still unknown.

Objectives: To evaluate the serum levels of IL-17 and IL-23 in Egyptian patients with $\mathrm{BD}$ and evaluate the correlations between the level of inflammatory cytokines and psychiatric manifestations as cognitive impairment, depression and anxiety. Methods: Study design and recruitment

In a case control study, we recruited $45 \mathrm{BD}$ patients, who fulfilled the modified International Criteria for Behçet's Disease (ITR-ICBD 2014) from the Rheumatology and Rehabilitation Department, Assiut University hospital. Thirty apparently healthy sex and age matched subjects were recruited, served as controls. This study was approved by the Ethical Committee of the Assiut University, Egypt Informed consent was obtained from all participants.

Study methodology

All patients and controls were assessed for cognitive impairment, depression and anxiety using memory assessment scale, Hamilton depression rating scale and Hamilton anxiety rating scale respectively. 